\title{
O AMADURECIMENTO DE UMA ARQUEOLOGIA HISTÓRICA MUNDIAL
}

\author{
Pedro Paulo A. Funari \\ Dept $^{\circ}$ de História - IFCH/UNICAMP
}

Os últimos anos testemunharam uma verdadeira revolução no campo da Arqueologia Histórica internacional, destacando-se, em particular, a realização, pela primeira vez com esse nome, de um tema intitulado Changing Perspectives on Historical Archaeology, no contex to do World A rchaeological Congress 3, realizado, em Nova Delhi, em dezembro de 1994. O tema, organizado por uma européia (Sian Jones, Southampton), um africano (Martin Hall, Cape Town) e um sul-americano (Pedro Paulo A. Funari, Campinas), contou com quatro subtemas: 1 . explorando questōes epistemológicas: problemas de definição do objcto (organizado por Funari); 2. a pluralidade da cultura material: raça, etnicidade, tribo, classe e gênero (Jones); 3. a Arqueologia e a representação das identidades modernas: nacional, colonial, imperial (Timothy Champion); 4. Arqueologia feminista (Suzanne Spencer-Wood). No total, 49 papers foram apresentados por autores provenientes dos cinco continentes. Cronologicamente, os trabalhos abrangeram desde a antiga Palestina (S. JONES, 1994) ou a Bretanha Romana (HINGLEY,
1994) até a atualidade (e.g. LEVI, 1994). Os organizadores do tema preparam a publicação de um volume da série One World Archaeology', publicada pela editora Routledge, a sair em 1997.

Paralelamente ao evento na Índia, foram lançados, em inglês, dois volumes sobre o tema que, em pouquíssimo tempo, tornaram-se text books, ambos de autoria de Charles E. Orser, Jr. O público brasileiro foi privilegiado com a publicaçāo de um manual, traduzido para o português e inédito em inglês, que adiantaria diversas idéias que, desenvolvidas, estão presentes nos livros-textos publicados nos Estados Unidos; essa pequena obra (ORSER, 1992), ainda que em nosso idioma, chamou atenção no exterior, tendo sido resenhada, de forma muito positiva, em Historical Archaeology (ESAREY, 1995). Orser uniu-se a Brian Fagan para apresentar um manual muito didático introdutório à Arqueologia Histórica (ORSER \& FAGAN, 1995), cujo imenso êxito editorial explica-se não apenas pelas inovaçōes metodológicas como pela abrangência de tópicos tratados. De fato, o livro discute a definição da Ar- 
queologia Histórica, sua História, os sítios e artefatos, as noçōes de tempo e espaço, as prospeç̧ōes, o trabalho de campo, as icorias explicativas, os grupos, sua difusão pelo globo e a dimensão política deste campo de estudo. Pouco após a publicação deste manual, Orser (1996) apresentou sua grande obra, interpretativa e inovadora, cuja leitura trouxe-me à mente as palavras de Cícero (Acadenicae Quaestiones, 1,1,2): habeo opus magnum in manibus! De fato, Orser começa seu livro com um capítulo significativamente chamado "Uma crise na Arqueologia Histórica" $c$ utiliza-se dos restantes sete capítulos para propor um estudo interdisciplinar da cultura material do capitalismo.

Neste contexto, caberia discutir, aqui, algumas das questōes cpistemológicas centrais subjacentes às alterações em curso na Arqueologia Histórica. A primeira delas refere-se ao seu caráter inter e multidisciplinar. Nāo é casual que, ao mesmo tempo que ocorriam as sessões na Índia e lançavam-se esses livros, um grupo de cientistas resolvia iniciar a publicação de um novo periódico acadêmico, Journal of Material Culture, cujo primeiro número veio à luz cm 1996. No editorial, Daniel Miller e Christopher Tilley propunham que "o fato de não existir uma disciplina chamada 'estudo da cultura matcrial' pode ser visto como uma vantagem. Disciplinas, com seus mecanismos de manutençīo de frontciras, com estruturas institucionais, textos básicos, metodologias, debates internos e áreas de estudo delimitados, por sua própria constituição, são de naturcza conservadora... nosso objetivo... consiste $\mathrm{cm}$ cncorajar a fertilização por cruzamento de idéias e abordagens entre pessoas preocupadas com a constituição material das relaçōes sociais" (MILLER \& TILLEY, 1996, p.5; cf. DEETZ, 1977, p12).

Essa multidisciplinaridade encontra-se na própria definiçāo da árca em Orser \& Fagan (1995, p.14): "a Arqueologia Histórica é um campo multidisciplinar que compartilha uma relação especial com as disciplinas formais da Antropologia e da História". Como propōe Orser (1996, p.11), "hoje podemos dizer que, para muitos estudiosos, História e Antropologia sāo distintas apenas em um sentido 'trivial de especialização acadêmica' " (cf. ORSER, 1994, p.6). Outras disciplinas sāo também, explicatamente, citadas, como Geografia, Sociologia, Arquitetura, Semiótica $\mathrm{e}$ a julgar pelas discussōes ocorridas na India, deve acrescentar-se a Filosofia (e.g. MORAES, 1994), o cstudo do patrimônio (c.g. HINGLEY, 1994) ou a História da Arte (e.g. RHYNE, 1994). Talvez quem melhor tenha se expressado, a esse respeito, tenha sido Pierre Bourdicu (1996, p.7I), cm recente entrevista: Grosse Historiker der Vergangenheit, wie Kantorowicz, Panofsky, Marc Bolch, Braudel, Gerschenkron, Finley oder E.P. Thompson haben aus ihrer Praxis heraus Theorien entwickelt wie alle anderen Spezialisten der Sozialwissenschaften auch, indem Sie die Gesamineit theoretischer Erkennmisse aller Sozialwissenschaften kumulierten. A rclação estrcita entre a Arqueologia Histórica e a História induziu David Austin (1990, p.29) a propor sua unificação, como uma cspécie de História social (cf. CERDȦ, 1991, p.420). Com efeito, documentos escritos c cultura matcrial são, ambos, objetos de estudo inseparáveis (cf. NOËL HUME, 1969, p.13; ORSER, 1987, p.131; NUNES, 1994, p. 181; D'AGOSTINO, 1995, p. 104).

A definição exata de Arqueologia Histórica contitui, provavelmente, a questão mais controversa na atualidade. Orser \& Fagan (1995, p.14) propōem que ela seja uma disciplina que "centra sua atenção no passado pós pré-histórico, e procura entender a natureza global da vida moderna". Trataria do período posterior a circa 1415 (tomada de Ceuta), caracterizado por quatro haunts: colonialismo, eurocentrismo, capitalismo e modernidade (ORSER, 1996, pp.57-88 et passim), termos indissociáveis e relacionados à expansāo européia (CHAMPION, 1990, p.92). Esta proposta pode ser avaliada a par- 
tir de duas questōes centrais, às quais particular contribuição tem sido dada pelos historiadores. Em primeiro lugar, pode falar-se em continuidade histórica entre o século XV e o presente, continuidade essa que derivaria, precisamente, do capitalismo? Eric Hobsbawn (1985, p.13) lembra que a própria palavra "capitalismo" só foi introduzida na década de 1860; no entanto, usa-se o termo "capitalismo comercial ou mercantil" para designar o predomínio dos interesses burgueses desde o século XV. Embora a produção não fosse capitalista, baseada no trabalho assalariado, poder-se-ia concordar com Caio Prado Júnior e supor que "a análise da estrutura comercial de um país revela, sempre, melhor que a de qualquer um dos seus setores particulares da produção, o caráter de uma economia, sua natureza e organização (PRADO, 1966, p.266; cf. TAVARES, 1967, p.57). O caráter capitalista do período moderno, ainda mais no que se refere às áreas periféricas, como as regiōes da América dominadas pela escravidão, foi destacado por Fernando Novais (1970, p.33; cf. TOPIK, 1991, p. 1375) e pode dizer-se que muitos estudiosos compartilham da certeza de Frédéric Mauro (1970, p.19) de que "capitalismo comercial e capitalismo industrial têm estruturas próprias, <mas> mecanismos gerais e estruturas gerais comuns" (cf. CHAUNNU, 1984, p. 427).

Outros, contudo, não aceitam tais generalizações e continuidades, pois "a economia das tempos modernos (da metade do século XV até a metade do século XVIII) é fundamentalmente pré-capitalista, o que se aplica à Europa, ao mundo colonial a ela submetido, e ao incipiente mercado mundial" (CARDOSO \& BRIGNOLI, 1983, p.73). O modo de produção escravista colonial das Américas não seria, eo ipso, capitalista (GORENDER, 1978; CARDOSO, 1982; cf. BEOZZO, 1978, p.287). Nos aspectos sócio-culturais, com mais forte razão, pode caracterizar-se as sociedades modernas, em particular ibéricas, americanas e africanas, como dominadas por instituiçōes patriarcais, com divisões nāo apenas de classe como de status, não igualitárias, no sentido capitalista do termo, mas hierarquizadas (Rangel, 1978, pp. 85, 88, 90, 92 et passim; Rangel, 1981, pp. 5,8; Thornton, 1981, p.186 et passim; Thornton, 1992, passim; Da Matta, 1991, p.399). Seria, neste contexto, possível uma Arqueologia do Capitalismo, no sentido amplo, dar conta dessa complexidade? Barbara Little (1994, pp.15-16) não tem dúvida a respeito:

"Focalizar o capitalismo e o desenvolvimento da ideologia dominante no mundo modemo ocidental é importante. Há pontos débeis, contudo, dos quais não é o menor o ponto de vista centrado no ocidente europeu, que pode servir para omitir da 'Arqueologia Histórica' trabalhos transculturais relevantes que incorporam documentação escrita, como aquela referente aos Estados pré-capitalistas do Velho Mundo, às manobras políticas entre grupos nativos americanos, na Europa medieval ou nas cultura africanas documentadas pela História oral".

Assim, embora o "mundo moderno seja caracterizado por uma economia única que é colonial, internacional e em expansão" (ORSER, 1996, p. 83) e o arqueólogo lide com artefatos que são commodities (ORSER \& FAGAN, 1994, p.83), mercadorias voltadas para a troca comercial, esse mundo complexo incluía realidades ligadas de modo apenas parcial ao capitalismo. Dois exemplos tratados na Índia e nos livros em questão podem exemplificar bem isso: a cultura material quilombola, em Palmares (ROWLANDS, 1994; ALLEN, 1995; FUNARI, 1995) e a cultura material dos africanos escravizados no sul dos Estados Unidos (ORSER, 1996, pp. 117-123). Quanto a esta última, o estudo da chamada cerâmica $\mathrm{Co}$ lono ware, que compreende de 80 a 90 por cento de toda cerâmica encontrada em sítios de escravos no século XVIII (SINGLETON, 1991, p.161), demonstra tratar-se de uma produção que, mais que retornar aos costumes africanos ou indígenas, "conotava um sistema de resistência e diversidade cultural que buscava diferenciar-se da cultura européia dominante" 
(ORSER, 1996, p. 121). Os escravos não queriam tanto ser africanos ou americanos, ou fazer parte de grupos étnicos específicos, mas mostrarem-se diferentes dos opressores (HALL, 1992, p. 385).

A cultura material palmarina, recém-descoberta e estudada, demonstra uma mescla de características indígenas, africanas e européias, resultante em uma espécie de sincretismo (ALLEN, 1995), cujas particularidades não se explicam apenas pelo capitalismo mas sem o qual não se pode entender (cf. FUNARI, 1996). Neste sentido, pode concordar-se com Orser que o capital, direta ou indiretamente, transformou e imprimiu cspecificidades ao mundo pós-medieval. Por outro lado, os organizadores do tema Changing Perspectives in Historical Archaeo. logy, na Índia, preferiram optar por uma definição mais abrangente do termo Arqueologia Historica. $\mathrm{Na}$ verdade, como lembrou, há pouco, Kent Lightfoot (1995, pp. 200, 202, 210, 211), a própria divisão entre História e Pré-História pode dificultar o conhecimento do passado:

\footnotetext{
"A atual separaçāo das Arqueologias Hisıórica e Pré-Histórica desvia-nos, em grande medida, do estudo da mudança cultural de longo prazo, especinlmente em contextos multiculturais...A divisão artificial entre Arqueologia 'histórica' e 'pré-historica' possui longa história na América do Norte, estando sua origem em uma antiga visão segregada do passado. Aldeias indígenas eram vistas como entidades distintas e separadas dos assentamentos europeus e euro-americanos e seu estudo envolvia grupos diversos de pesquisadores...<Contudos o estudo da mudança cultural de longo prazo, tanto ein contextos históricos como pre-historicos, $e$ imprescindível para avaliar todas as implicaçōes da exploraçĩo colonial e da formação de comunidades coloniais multi-étnicas...O potencial da Arqueologia para contribuir para os estudos dos contatos culturais é prejudicado pela prevalecente prática de dividir a História e a Pré-História em sub-áreas separadas".
}

Além disso, em um contexto mundial e extraamericano, a definição da Arqueologia Histórica como o estudo "da difusão $e$ manifestação da cultu- ra moderna por todo o mundo" (ORSER, 1988, p.5) parece dar conta de apenas uma parte da questāo, pois continuidades milenares podem ser tāo ou mais importantes que a crescente europeizaçāo do globo. A posição epistemologica por nós adotada, enquanto organizadores do tema em WAC 3, foi privilegiar um elemento essencial de nosso objeto de estudo: o caráter de classe das sociedades históricas. Admitindo-se as continuidades entre a História e a Pré-História assinaladas por Lightfoot, não se pode deixar de notar a diferença entre sociedades ágrafas e sem Estado $\mathrm{e}$ as sociedades hierarquizadas, alfabetizadas e caracterizadas por divisōes de classe e pela exploração. Neste sentido, a Arqueologia Histórica estuda, justamente, esta interação entre dominantes e dominados, letrados $\mathrm{c}$ iletrados, em diferentes contextos culturais e cronológicos. A Arqueologia Histórica, portanto, "democratiza o passado, iluminando a vida quotidiana das pessoas comuns que não são visívcis no registro documental" (HALL, 1991, p.78). Não se estuda apenas a upper crust (HALL, 1993, p. 182), mas a cultura dos escravos (SINGLETON, 1990, p. 72), dos trabalhadores, em geral (NEGRI, 1991, pp. 383-384). O estudo dos iletrados, naAtenas Clássica, como demonstra o trabalho de Louise Zarmati (1994) apresentado na Índia, nāo dispensa o uso da metodologia da Arqueologia Histórica do mundo moderno, mas não se esgota nela $\mathrm{c}$, de uma forma ou de outra, fornece elementos para que se possa repensar a própria Arqueologia do mundo pós-medicval. A Arqueologia Histórica talvez pudesse ser definida, portanto, como aquela que estuda as contradições inerentes às sociedades de classe (cf. HALL, 1994, p. 1).

O amadurecimento de uma Arqueologia Histórica mundial, nos anos noventa, implica em superar algumas limitaçōes. Em primeiro lugar, seu caráter multidisciplinar exige a superação das barreiras formais entre as disciplinas acadêmicas que lidam com as sociedades humanas e sua transformaçāo. $O$ es- 
tudo da cultura material define a Arqueologia mas ele não pode ser feito de forma isolada, nem confundido com a mera e ilusória "produção de fatos novos" - uma escavação, por exemplo. Em segundo lugar, encarada como estudo da difusão européia pelo mundo ou como análise das contradiçōes materiais nas sociedades de classe, a Arqueologia Histórica tem como centro de sua atençāo as tensões sociais, no passado e no presente. Reconhece-se como resultado dos conflitos contemporâneos e parte do pressuposto de que para conhecer o passado é necessário conhermos a nós mesmos (SHANKS \& TILLEY, 1987). Por fim, mas não menos importante, há um componente ético, tanto na academia como fora dela, cuja essência consiste no pluralismo e no respeito à

\section{Bibliografia}

ALLEN, S.J.Africunisms, Mosaics, and Creativity: the Historical Archaeology of Palmares. Rhode Island, Brown University. master's thesis, 1995.

AUSTIN, D. "The 'proper study' of medieval archaeology". In: AUSTIN, L. \& ALCOCK, L. (eds), From the Balitc so the Black Sea. Studies in MedievalArchaeology. Londres, Unwin Hyman, 1990, pp.10-42.

BEOZZO, J.O. "Rescnha". Encomtros da Civilizaçāo Brasileira, I, 1978, pp. 286-292.

BOURDIEU, P. "Über die Beziehungen zwischen Geschichte und Soziologic in Frankreich und Deutschland". Ceschichte und Gesellschuft. 22 (1), 1996, pp.62-89.

CARDOSO, C.F. \& BRIGNOLI, H.P. Hisfriria econômica da América Lutina. Rio de Janeiro, Graal, 1983.

CARDOSO, C.F.S. Agriculura. escravidão e capitalismo. Rio de Janeiro, Vozes, 1982.

CERDȦ, M. "Industrial archneology and the working class". Arqueulogia Industrial, Valencia, 1991, pp. 403-422.

CHAMPION, T.C. "Medieval archaeology and the tyranny of the historical record". In: AUSTIN, D. \& ALCOCK, L. (eds), From the Balsic io the Black Sea. Studies in Medieval Archaeology: Londres, Unwin Hyman, 1990, pp.79-95. divergência, na transparência que não oculta golpes e que permite a visibilidade das opressões e contradições, no passado e no presente.

\section{Agradecimentos}

Agradeço aos seguintes colegas que, de uma outra de outra forma, permitiram a redação deste ensajo: Scott Allen, David Austin, Timothy Champion, Edgar de Decca, Martin Hall, Richard Hingley, Sian Jones, Sarah Tiziano Levi, Kent Lightfoot, Barbara Little, João Quartim de Moraes, Charles E. Orser, Jr., Theresa Singleton, Suzanne Spencer-Wood, John Thornton e Louise Zarmati. As idéias são, naturalmente, de exclusiva responsabilidade do autor.

CHAUNNU, P. Conquista e exploraçāo dos novos mundos (stculo XVI). Sđa Paulo, Pioneira, 1984.

D'AGOSTiNO, M.E. "Review". Historical Archaeslogy, 29 (1), 1995, pp. 103-104.

DA MATTA, R. "Religion and modernity: three studies of Brazilian religiosity". Journal of Social History, 25 (2), 1991, pp. 389-406.

DEETZ, J. "Material culture and archaeology - what's the difference". In: FERGUSON, L. (ed), Historical Archaeolugy and the Importance of Material Things. Nova Jorque, Society for Historical Archaeology, 1977, pp. 9-12.

ESAREY. M.E. "Review of Charles E. Orser's Introdução à Arqueologia Histirica, translated by Pedro Paulo Abreu Funari, Oficina de Livros, Belo Horizonte, 1992, 142 pp.". Historical Archaeology, 29 (2), 1995, pp. 131-132.

FUNARI, P.P.A. "The archaeology of Palmares and its contribution to the understanding of the History of African-American culture". Historical Archaeology in Lasin America, 7, 1995, pp. 141 .

FUNARI, P.P.A. Novas perspectivas abertas pela Arqueologia da Serra da Barriga. Sĩo Paulo. manuscrito inédito, a ser publicado por Lilia M. Schwarez, Companhia das Letras, 1996. 
GORENDER, J. O escravismo colonial. São Paulo, Ática, 1978.

HALL, M. "Fish and Fisherman, archaeology and art: Cape Town seen by Bowler, D'Oyly and De Meillon". S. -Afr. Tydeskr. Kuns-Argit-Gesk, 2 (3/4), 1991, pp. 78-88.

HALL, M. "Small things and the mobile. conflictual fusion of power, fear, and desire". In: YENTSCH, A.E. \& BEAUDRY, M.C. (eds). The Art and Mystery of Historical Archaeology: Essays in Honor of James Deetz.Boca Raton, CRC Press, 1992, pp. 373-399.

HALL, M. "Subaltern voices? Finding the spaces between things and words". World Archaeological Congress 3. 1994.

HALL, M. "The archacology of colonial settement in Southern Africa". Annual Review of Anthropology, 22, 1993, pp. 177. 200.

HINGLEY, R. "A post-colonial perspective on change in Roman Britain". World Archaeological Comgress 3, 1994.

HOBSBAWN, E.J. The Age of Capital: 1878-1875. Londres, Abacus.

JONES, S. "Historical categories and the praxis of ethnicity: a critique of the interpretation of ethnic groups in ancient Palestine". World Archaerological Congress 3, 1994.

LEVI, S.T. "Women's work in Italian archaeology". World Archaeological Congress 3. 1994.

LIGHTFOOT, K.G. "Culture contact studies: redefining the relationship beiween prehistoric and historical archueology". American Antiquity. 60 (2), 1995, pp.199-217.

LITTLE, B. "Pcople with history: an update on historical archeeology in the United States". Journal of Archaeslogical Meshod and Theory, 1 (1). 1994. pp. 5-40.

MAURO, F. "O papel do comércio extcrior no capitalisıno comercial e no capitalisıno industrial". Estudos Históricos, 9. 1970. pp. 19-26.

MILLER, D. \& TILLEY, C. "Editorial". Journal of Material Culture, I, 1996, pp.5-14.

MORAES, J.Q. “Trois visées sur 1'Orient: Voltaire, Marx et Reclus". World Archaeological Congress 3, 1994.

NEGRI, A. "Industrial archaeology and material culture". Arqueologia Indusirial, Valencia, 1991, pp. 393-401.

NOËL HUME, I. HistoricalAnchaeology. Nova lorque, Knopf, 1969.

NOVAIS, F. "Sistema colonial, industrializaçāo e etapas de desenvolvimento". Estudos Históricos, 9, 1970, pp. 27-37.

NUNES, J.P.A. "Inventores, registros de pantentes e de marcas $\mathrm{e}$ Arqueologia industrial: um excmplo concreto". Revista Portuguesa de História, 29, 1994, pp. 181-212.

ORSER, C.E. "Plantation status and consumer choice: a materi- alist framework for historical archaeology". In: SPENCER. WOOD, S. (ed), Consumer Choice in Historical Archaeology. Nova lorque, Plenum, 1987, pp. $121-137$.

ORSER, C.E. "Toward a global historical archacology: an example from Brazil". Historical Archaeology, 28 (1), pp. 5-22.

ORSER, C.E. The Material Basis of the Pust Bellum Tenant Plantation. Historical Archaeolgy in the South Carolina Piedmont. Athens, University of Georgia Press, 1988.

ORSER, C.E. \& FAGAN, B.M. Historical Archaeology. Nova Jorque, HarperCollins, 1995.

ORSER, C.E. A Historical Archaeology of the Modern World. Nova lorque, Plenum Press, 1996.

ORSER, C.E. Introdução à Arqueologia Histórica. Belo Horizonte, Oficina de Livros, 1992.

PRADO. C. Formação do Brasil Contemporaneo. São Paulo, Brasiliense, 1966.

RANGEL, I. “A História da dualidade brasileira”. Revista de Economia Política, 1(4), 1981, pp.5-34.

RANGEL, I. "Dualidade e 'escravismo colonial' ". Encontros com a Civilizaçāo Brasileira, 3, 1978, pp. 79-92.

RHYNE, C.S. "The complexity of cultural identity in the art of Pacilic Northwest Native Americans". World Archaeological Congress 3, 1994.

ROWLANDS, M. "Black identity and a sense of the past in Brazilian national culture". World Archaeslogical Congress 3, 1994.

SHANKS, M. \& TILLEY, C. Re-constructing Archaeslogy. Cambridge, Cambridge University Press, 1987.

SINGLETON, T. A. "The archaeology of the plantation South: a review of approaches and goals". Historical Archaeology. 24 (4), 1990, pp. 70-77.

SINGLETON, T.A. "The archacology of slave life". In: CAMPBEL.L. D.C. (ed), Before Freedom Came. Richmond, Museum of Confederacy, 1991, pp. 155-175.

TAVARES, A. "Caio Prado e a teoria da Revoluçäo Burguesa". Revista Civilizacaio Brasileira, 11/12, 1967, pp.48-80.

THORNTON, J. "Early Kongo-Portuguese relations: a new interpretation". History in Africa, 8, 1981, pp. 183-202.

THORNTON, J. Africa and Africans in the Making of the Allantic World, 1400-1680. Caunbridge, Cambridge University Press, 1992.

TOPIK, S.C. "Compte-rendu". Annales E.S.C., 50 (6), 1995. pp. 1374-5.

ZARMATI, L. "The archaeology of gender: problems of accessing non-literates in 'literate' Classical Athens". World Ar. chueological Congress 3, 1994. 